\title{
CONSIDERING SUSCEPTIBILITY OF INDIVIDUALS TO DIGITAL FINANCE AS A FACTOR OF INCREASING ITS PROSPERITY
}

\author{
DIVAEVA E. ${ }^{1}$, KUKHARENKO Olesya. ${ }^{2}$, GIZYATOVA Aliya ${ }^{3}$ \\ ${ }^{1}$ Russian Federation \\ ${ }^{2}$ Russian Federation \\ ${ }^{3}$ Russian Federation \\ divaeva@mail.ru', ol.kukharenko@gmail.com ${ }^{2}$,giza70@rambler.ru ${ }^{3}$
}

\begin{abstract}
The analysis of trading volumes of financial assets of FEC in Russian Federation for the part of private investors has demonstrated that the interest of individuals in the financial markets had increased in 2020. Society's susceptibility to digital finance is closely related to digitalization of brokerage services, which is realized through making adopted for mobile digital platforms and digital products users. Low level of digital literacy of individuals in common on the territory of Russian Federation was not an impediment to growth of digital competences in 2020.

The share of brokerage accounts of individuals on Moscow Exchange (MOEX) has increased by 193\% in 2020 due to that individuals are looking for alternative ways to save their personal savings against the background of increasing digital financial literacy among the working-age population. Russian brokers are improving the quality of their information and analytical digital resources that aggregate large amounts of statistical information for wide access for interested private investors who have developed digital competencies and want to improve their financial and investment literacy.
\end{abstract}

Keywords digitalization of brokerage services, digital literacy of individuals, mobile digital platforms, digital products and services

JEL:G00

DOI: $10.5937 /$ intrev2102139D

UDC: 005.942:330.322.1(470)

004.7:339.13

COBISS.SR-ID 43521545 


\section{INTRODUCTION}

Digitalization of finance provides broad investment opportunities that affect the well-being of society and at the same time puts forward new requirements for market participants. In the context of the growing interest of the population in the financial market, the pattern is an increase in the sensitivity of society to digital finance. The susceptibility to digital finance is closely correlated with the digitalization of brokerage services, which is realized through the creation of digital platforms and digital tools adapted for users by brokers. Modern digital platforms create favorable investment conditions for users who are ready to perceive the digital financial environment and improve their financial literacy.

Global trends of advanced technologies implementation have led towards the faster pace of digitalization of the financial. Implementation of digital technologies has led to enforcement of financial institution's position and to increasing of their interaction level with clients on the base of innovative approach for financial product's promotion and services among private investors. Digitalization of financial sphere, being an integral feature of the development of the modern world economy is characterized by high dynamics, which leads to the emergence of new requirements for financial market participants, its institutions and users of financial services. Implementation of electronic-digital technologies in all spheres of financial market, including in organization of exchange business, provides access to different financial tools and apps, and firstly, to major companies stocks of leading economic spheres for unlimited for unlimited range of users and opens up new opportunities of getting additional sources of income and achieving financial prosperity. New digital surrounding medium has its requirements to competencies of its users. Private investors, having digital investment skills are becoming human capital stimulating the capacity of the stock market [1]. The society's susceptibility to acceptance of digital financial sphere from the point of view of moral and psychological readiness of private investors to navigate in digital financial services and products offered in the financial market and the desire to improve their digital investment literacy has important meaning in conditions of digitalizing. The moral and psychological readiness of the individuals is understood as their readiness for an innovative way of thinking, the ability to perceive innovations without resistance. The major impediment to the acceptance of digital financial technologies by society is the fear of uncertainty, personal innovation conflict, lack of time for development and risk phobia. Digital literacy should be understood as the advanced competencies of individuals related to the procession of digital technologies for practical use in everyday life and economy of households. Investment literacy of individuals is combination of knowledges, skills and emplacements, allowing the individual to make financial and investment decisions regarding personal finances and investments.

\section{METHODOLOGY}

The aim of the study is the evaluation of Russian society's susceptibility to digitalization of financial and investing services from the point of possessing digital and investment literacy.

The data of expert's surveys performed by analytical center NAFI (multifunctional analytical center), Higher school of Economics (Moscow) for 2020 year and statistical data from Moscow Exchange (MOEX) is the empiric base for the study.

Comparative analysis and focus group are major methods of study.

The object of study is Russian society interest in increasing private prosperity.

The subject of study is cognitive susceptibility of Russian society that responds to the incentives of digitalization of financial markets and is able to solve investment problems independently.

\section{STUDY RESULTS}

According to some experts, Russian society has not insufficiently developed digital financial competencies. For example, based on the data as on November 2020 of NAFI analytical center, Digital financial literacy index of Russians was 26,69 scores of 100 possible scores. $44 \%$ of Russians have middle level of digital financial literacy. 35\% of Russians were evaluated with low level of digital financial literacy, this group includes mainly residents of rural areas, people with poor financial conditions, as well 
as citizens of mature age. Each $5^{\text {th }}$ citizen of Russian Federation has high level of digital financial literacy $(21 \%)$, mainly it is younger people, people with high income, citizens of middle and large Russian cities. One third of Russians (35\%) does not use digital technologies for finance management and distance banking services [2].

Digital skills of Russians can be divided in the following directions of progression:

- informative skills;

- communicational skills;

- solving problem skills;

- working with program software.

Informative skills include: copying or moving a file or folder, saving files in online storage, getting information on products and services, searching for health-related information.

Communicative skills include: sending or receiving e-mail, activity in social networks, phone or video calls per internet, uploading own content on any web-site.

Solving problem skills include: files distribution between computers or other devices, software and apps installing, changing settings of any software, including operational system or safety programs, online shopping (for the last 12 months), online sales, using online studying resources, internet-banking.

Working with program software include: working with text editor, with electronic tables, editing photo-, video- and audio files, creating presentation or document, which contains text, figures, tables or diagrams, using extended functions of electronic tables for organization and data analysis, writing the code in program language [3].

For example, lots of activities related with computer using and other electronic devices (for example such as installing/setup of program software, distribution of files between devices) are performed by Russians much less often than by citizens of European countries. Partly the reason of that is that in lots of companies such activities are in responsibility of IT-specialists. Furthermore, the underrunning in level of skills possession, which is traditionally associated with office work: using e-mail, text editor, working with electronic tables, creating of presentations, is observed, is observed. Using of any program language in everyday activity is still the unique and narrowly specialized skill. More than a half of Russians who is older than 15 years use social networks and regularly make telephone calls or videocalls using technologies, which are provided by the internet-connection [3].

Private finance is the one of the main spheres of human's social living. In addition, it is the financial sector that became one of the first to be digitalized in the national economy, and outstripped the growth of digital competencies in this area among individuals.

Insufficient digitalization of personal finances of Russians was explained by:

low internet occurrence in the territory of Russian Federation, for example, each $5^{\text {th }}$ Russian citizen has never used Internet;

historically established suspiciousness of households to stock papers;

economically determined reasons for the low interest of citizens in personal financial savings and pension plans.

Table 1:Level of digital skills possessing in the age groups of Russian individuals, \%

\begin{tabular}{|c|c|c|c|c|c|}
\hline \multirow[b]{2}{*}{ Age group } & \multicolumn{5}{|c|}{ Digital skills, \% } \\
\hline & $\begin{array}{l}\text { Higher than } \\
\text { basic level }\end{array}$ & $\begin{array}{l}\text { Basic } \\
\text { level }\end{array}$ & $\begin{array}{l}\text { Low } \\
\text { level }\end{array}$ & $\begin{array}{l}\text { Absence of } \\
\text { skills }\end{array}$ & $\begin{array}{l}\text { Do not use internet for the last } \\
\text { three months }\end{array}$ \\
\hline $15-24$ years & 22,4 & 36,8 & 37,1 & 1,2 & 2,5 \\
\hline $25-34$ years & 18,7 & 34,9 & 41,9 & 0,9 & 3,7 \\
\hline $35-44$ years & 15,7 & 31,8 & 45 & 1,4 & 6,2 \\
\hline $45-54$ years & 11,5 & 26,5 & 47,6 & 1,8 & 12,7 \\
\hline $55-64$ years & 4,9 & 15,5 & 44,2 & 2,8 & 32,6 \\
\hline $65-74$ years & 1 & 6,2 & 28,7 & 3,5 & 60,5 \\
\hline $\begin{array}{l}\text { older than } 75 \\
\text { years }\end{array}$ & 0,2 & 1 & 7,2 & 2,5 & 89,1 \\
\hline Total & 11,9 & 24,5 & 39,3 & 1,9 & 22,5 \\
\hline
\end{tabular}

Source: E.I. Leven, A.B. Suslov [3] 
Analyzing data of Table 1, which presents the results obtained by Higher school of Economics, it is clear that data do not fundamentally differ from the NAFI data presented above in the present article. Russian individuals in common in the range $35-39 \%$ of the total number has low level of digital competencies.

The younger generation of users (age 15-24 years) having advanced digital skills, at the same time have a low level of financial and investment literacy.

Individuals of working age making a career (age group 25 - 54 years), possess digital competencies at a basic level.

One of the indicators of society's integration into the digital economy is its involvement in the investment process through online trading, which is characterized by the share of private investors-stock market participants in the total population.

According to the data of the MOEX, the number of unique individual clients in the Trading System as of 31.12.2020 was 8,787,077 [4]. According to preliminary data published on the Rosstat website, the population of Russia as of 01.01 .2021 is estimated at $146,238,185$ people [5]. Thus, today approximately $6 \%$ of the population participate in trading on the MOEX as individuals.

Until recently, in Russia, this indicator was very low and at the end of 2019, based on the number of individuals with customer accounts of 3,859,911 (as of 31.12.2019) and reached only $2.6 \%$ of the total population on the corresponding date.

Table 2:Dynamics of the number of unique clients in the Trading System

(as of the last day of the month)

\begin{tabular}{|l|c|c|c|c|}
\hline \multicolumn{1}{|c|}{ Client groups } & December 2020 & January 2021 & February 2021 & March 2021 \\
\hline Individuals & 8787077 & 9412672 & 10296032 & 11050505 \\
\hline Legal entities & 19014 & 19074 & 19173 & 19312 \\
\hline Foreigners & 17268 & 17041 & 17445 & 17990 \\
\hline Foreign nationals & 14515 & 14288 & 14651 & 15185 \\
\hline Foreign legal entities & 2753 & 2753 & 2794 & 2805 \\
\hline $\begin{array}{l}\text { Clients who have transferred } \\
\text { their funds to the trust } \\
\text { management }\end{array}$ & 79270 & 82193 & 86734 & 110250 \\
\hline \multicolumn{1}{|c|}{ Total } & 8902629 & 9530980 & 10419384 & 11198057 \\
\hline
\end{tabular}

Information resource on the base of the MOEX data.

Access mode: https://www.moex.com/s719

Paradox of 2020 year is the fact that number of individuals, which have brokerage accounts has expanded for about 5 millions persons and reached record 8,8 millions of persons, i.e. private investors, which had come on the arranged stock market for 2020 year - on the base of MOEX data, has expanded for more than 2 times. On the base of possessing digital competencies analysis, we can suppose that such expanded growth has happened in group of individuals of working age (25-54 years) having only basic digital skills.

This indicator continues to grow steadily, only in the three months of 2021, the growth of individual customer accounts amounted to 23.83\% (in January - 7.12\%, in February - 9.38\%, in March -7.33\%) (Table 2).

In 2020 year private investors inset 301 billion rubles in shares of Russian companies, investments in bonds amounted 617 billion rubles with the largest share of investments $(88,5 \%)$ accounted for corporate bonds. Individuals, novice investors, who starts to try their hand at the stock market for the first time, usually buy stocks and bonds, these are the main instruments that account for the main flow of individual investments. The most popular shares among Russians in 2020 year were shares of the oil and gas industry: «Gazprom» (23.1\%), «LUKOIL» (11.8\%), preferred shares of «Surgutneftegaz» (6.8\%). Russian oil and gas sector, which is a stable and steadily developing branch of the Russian economy, is attractive from an investment point of view for Russian inner private investor. The oil and gas industry, represented by the leading companies in this sector occupies the largest share in the Russian stock market and is its leader due to the established industry structure of the Russian economy. The fuel and energy complex serves as the basis of the Russian economy, and determines its export and raw materials orientation, since approximately $40 \%$ of primary energy resources are exported from Russia, and the share of the capitalization of the oil and gas industry of the leading companies in the total volume of the stock market accounts for $40.7 \%$ (Table 3 ). 
Table 3:Capitalization of the leading Russian emitents included in the industry index calculation database

\begin{tabular}{|l|l|l|l|}
\hline \multicolumn{1}{|c|}{ Industry indexes } & $\begin{array}{c}\text { The number of } \\
\text { securities included } \\
\text { in the industry } \\
\text { index calculation } \\
\text { database }\end{array}$ & $\begin{array}{c}\text { Total } \\
\text { capitalization, } \\
\text { Billion rubles. }\end{array}$ & $\begin{array}{c}\text { Share of } \\
\text { capitalization on } \\
\text { the stock market, } \\
\%\end{array}$ \\
\hline Consumer sector & 12 & 1939 & $3,4 \%$ \\
\hline Chemical and petrochemical industry & 6 & 1093 & $1,9 \%$ \\
\hline Finance & 9 & 8699 & $15,1 \%$ \\
\hline Electric power industry & 18 & 2114 & $3,7 \%$ \\
\hline Metals and Mining & 13 & 11911 & $20,6 \%$ \\
\hline Oil and gas & 11 & 23481 & $40,7 \%$ \\
\hline Telecommunications industry & 4 & 1035 & $1,8 \%$ \\
\hline Transport & 6 & 680 & $1,2 \%$ \\
\hline
\end{tabular}

Information resource on the base of the MOEX data.

Access mode: https://www.moex.com/ru/factsheet

There is data on market capitalization of the Russian giant emitents, companies of oil and gas industry, representing the «Oil and gas» industry index presented in Table 4.

Table 4:Market capitalization of the leading Russian emitents included in the calculation base of the "Oil and Gas industry index»

\begin{tabular}{|l|l|r|r|r|r|r|r|}
\hline № & $\begin{array}{l}\text { Instrument } \\
\text { code }\end{array}$ & $\begin{array}{c}\text { Price, } \\
\text { rub. }\end{array}$ & $\begin{array}{c}\text { Total number of } \\
\text { securities }\end{array}$ & Capitalization, rub. & $\begin{array}{l}\text { Free- } \\
\text { float }\end{array}$ & $\begin{array}{c}\text { Capitalization, } \\
\text { included in the index, } \\
\text { rub. }\end{array}$ & $\begin{array}{c}\text { Weight, } \\
\%\end{array}$ \\
\hline 1 & BANEP & 1281 & 29788012 & 38158443372 & 0,63 & 24039819324,36 & 2,01 \\
\hline 2 & GAZP & 224,52 & 23673512900 & 5315177116308 & 0,5 & 169796787845,59 & 14,2 \\
\hline 3 & LKOH & 5985 & 692865762 & 4146801585570 & 0,55 & 176817401069,87 & 14,78 \\
\hline 4 & NVTK & 1455 & 3036306000 & 4417825230000 & 0,21 & 188415386451,75 & 15,75 \\
\hline 5 & RNFT & 164,2 & 294120000 & 48294504000 & 0,11 & 5312395440 & 0,44 \\
\hline 6 & ROSN & 560 & 10598177817 & 5934979577520 & 0,11 & 176280775281,46 & 14,74 \\
\hline 7 & SNGS & 35,905 & 35725994705 & 1282741839883 & 0,25 & 103841768095,5 & 8,68 \\
\hline 8 & SNGSP & 42,55 & 7701998235 & 327720024899 & 0,73 & 77467340069,39 & 6,48 \\
\hline 9 & TATN & 597,2 & 2178690700 & 1301114086040 & 0,32 & 157288580005,41 & 13,15 \\
\hline 10 & TATNP & 560,5 & 147508500 & 82678514250 & 1 & 31233776506,58 & 2,61 \\
\hline 11 & TRNFP & 148900 & 1554875 & 231520887500 & 0,37 & 85662728375 & 7,16 \\
\hline
\end{tabular}

Information resource on the base of the MOEX data.

Access mode: https://www.moex.com/ru/index/MOEXOG/constituents/

The main reasons for increasing the interest of private investors in insetting in the stock market are:

- low rates on the capital market on deposits for individuals,

- depreciation of the ruble,

- the government's announced tax on interest on bank deposits,

- pandemic of COVID-19,

- lots of free time during self-isolation,

- popularization of distance learning, including financial literacy, among the population.

- Cognitive factors of increasing the susceptibility of Russians to making investments are:

- active financial advertising performed by banking and investment organizations in the mass media;

- popularization of investment activity in the stock market among population;

- active offer of free investment workshops in social networks;

- offers from banking and investment organizations on opportunity of connecting to digital platforms, which provide access for work on the stock market;

- free consulting support from financial news aggregators;

- open and free access to the ready analytics of stock markets;

- financially accessible service of brokerage accounts of the individuals wishing to invest in securities; 
- formation of the image of a successful and modern person in the presence of securities in the assets, obtaining passive income;

- stimulating state and tax policies in terms of citizens ' investment accounts [4].

Reaction of society on factors of digitalization financial and stock markets changes the susceptibility of citizens to digital finance and digital investments, making them more motivated and interested in receiving income from operations with securities of the stock markets. Using cognitive methods, Russian financial market expands its capacity by attracting individual investments. For example, on the base of National Securities Market Participants (NAUFOR) data on 2020 year, private investments on the stock market amounted to 6 trillion rubles, of which 5 trillion rubles were funds in brokerage accounts, while in 2019, private investment amounted to 3.2 trillion rubles, including 2.7 trillion rubles were funds in brokerage accounts [5].

Reaction of private investors on digital transformation of stock market is different. From one side, On the one hand, conservative private investors buy respectively trust bonds, but the share of such investors in 2020 decreased by almost 5\%. On the other hand, private investors have become more active in using brokerage accounts, buying stocks, ETFs, mutual funds. Private investors in common form medium-term and long-term stocks portfolios and do not have orientation for short-term speculative operations.

Digital invest platforms, located on smartphones of citizens have allowed to increase susceptibility of individuals to digitalization of stock markets. According to the criteria of the effectiveness of the strategy for attracting and serving customers in digital channels, the variety of the line of digital products and services, the convenience and functionality of websites and mobile applications, such Russian companies as JSC «Tinkoff Bank» (Tinkoff Investments), LLC «BKS Company» (BKS world of Investments), JSC «Finam Investment Company» (Finam) can be distinguished. 97\% of active private clients who make transactions on the Russian stock exchange operate through the top ten leaders in the field of brokerage services.

Online trading attracts a potential investor with its accessibility, external simplicity of making transactions and is a user interface that allows to monitor quotes online, place active orders, and monitor the status of private trading account. Modern electronic trading systems-trading terminals allow to perform technical analysis, export information to special data analysis programs, automate trading and accounting calculations, and use margin lending.

Digital media, digital economy and digital finance are closely related to such a concept, which is gradually coming into use, as a digital platform (digital platforms), which is a system of algorithmized relationships of a significant number of market participants, united by a single information environment, leading to a reduction in transaction costs, through the use of a package of digital technologies and changes in the system of division of labor. Thus, the process of disintermediation, i.e. the emotional perception of a person in the absence of an intermediary between a private investor and the stock market, also increases the sensitivity of the population to the digitalization of finance and investment. The sensitivity of users to digital finance is closely related to the digitalization of brokerage services, which, in relation to the brokerage service, is designed to solve the following tasks:

- speed of on-line customer service is a system of fast payments, instant transactions and ways of top up a remote account;

- expanding (maximization) of spectrum of brokerage services and financial products, which are oriented to different categories of clients, personalization of investing products;

- convenience, functionality, design, information content of websites, trading platforms and apps;

- various forms of training and advice to increase the trading activity of novice investors;

qualitative analytics and additional information on emitters.

Increasing the volume, speed of transactions and the ability to adapt services to customer needs is achieved through the use of new digital tools and digital platforms. The availability of financial services is increasing due to the emergence of new ways of providing them, and the product line for the consumer of investment services is expanding.

The rapid development of digital technologies and tools, their widespread use in the financial sector, is creating a new global digital environment.

One of the tasks of an investor in the formation of a medium - and long-term portfolio is the search for promising securities. Global information portals (platforms), such as Investing.com, offering a variety of global and local financial indicators for users. The availability, visibility, intuitive clarity and ease of 
use of such services allows to navigate in the right blocks of information both on the current stock quotes in real time, and at the same time on the group of companies, as in our example, included in the Index of the MOEX "Oil and Gas".

Such modern tools of high-performance operational stock market analytics allow users instantly get information: about the dynamics of changes in the value of the exchange rate of shares for a wide range of emitents, for example, the oil and gas industry, for certain time intervals; about the dividend yield, which is an important indicator of the investment attractiveness of shares and, at the same time, about the main financial indicators for a specific date.

The market value of shares depends on the economic performance of companies: profit, revenue, equity, profitability, revenue and equity, which are the basis for calculating the multipliers used by investors in making investment decisions and digital sources of aggregated statistical information make it possible to use ready-made financial indicators for private investors.

An important requirement for modern information and communication technologies is the speed of updating information. Exchange and financial information is variable in its content, rapidly changing, and should promptly reflect the events taking place in the market, because transactions in the modern financial market are concluded almost instantly. In order to increase the susceptibility of clients to brokerage services, digital financial products and active transactions on the stock exchange, brokers today face the task of providing functionality, ease of use and stable operation of mobile applications. Investment mobile apps are constantly being improved to attract new investors who want to connect to the stock market.

An indicator of the user's susceptibility to brokerage services is the constant growth of the client base in the digital channels of brokers. The MOEX provides statistics on the activities of leading brokers, which allows to track the dynamics of the activity of companies over a long period. Brokerage companies of the top ten serve $97 \%$ of active clients who make transactions on the stock exchange.

The leading positions in the field of brokerage services is occupied by «Tinkoff Investments». In 2020, «Tinkoff Investments» increased the number of attracted investors by 10 times, surpassing its competitors in terms of the number of active customers, and came out on top in Russia in this indicator.

Such a huge breakthrough was made possible, first of all, due to the high level of digitalization of this company, and ensuring maximum user susceptibility to digital finance through a convenient, functional, informative mobile application with ready-made investment ideas, which made trading in financial instruments as easy as possible for those who are just getting acquainted with the stock market. Other digital advantages, in addition to the functional mobile application, include fast withdrawal of funds and replenishment of the account via deposit cards. The activities of «Tinkoff Investments» and the resulting effect of the introduction of digital innovations clearly show how the growing demand of the population for digital technologies and the needs of potential customers (the ability to quickly make transactions using a smartphone and track quotes) determine an adequate offer from financial companies.

The other largest Russian broker is «BCS World of Investments», which accounts for approximately $20 \%$ of the turnover of the MOEX. BCS develops intelligent automated services for the selection of strategies and investment ideas for clients.

The Artificial intelligence service selects the most promising shares of Russian and international companies based on statistical data, compiles portfolios of selected securities, analyzes the state of the stock market, and gives trading signals to clients. The company tries to meet the requirements of digital time, providing its customers with convenient applications «BCS Online», «BCS Premier» and mobile applications «My Broker». All the main functions of the broker are available via a smartphone. Of particular interest are the information and news portal «BCS Express» and the training service «Investments 101».

The information and news portal «BCS Express», which publishes stock market and economic news, analytics and expert comments on investments and financial instruments, current quotes and stock prices online, helps investors to work effectively in the market.

In order to increase the digital financial literacy of the society, the Investment 101 training service offers more than 20 courses for everyone who wants to get primary knowledge and acquire skills in investing on the stock exchange. Modern electronic and digital platforms in the financial sector open up wide opportunities for private investment, and even allow the provincial population to acquire the skills of electronic trading, trade planning, and knowledge about new exchange-traded financial instruments. 
Modern means of information and communication technologies allow interested individuals to gain knowledge of the basics of technical and fundamental analysis for making short - term, medium-term, and long-term investment decisions.

The process of total digitalization has an impact on personnel trends, on changing the list of specialties and competencies demanded by employers. Mobile technologies today serve as a platform for digital business - this has led to the fact that today the most popular profession is the profession of a mobile application developer.

\section{CONCLUSIONS}

The digital age puts forward new competencies, skills in the field of obtaining new knowledge, and requirements for non-stop learning. Digitalization of finance provides broad investment opportunities that have an impact on the well-being of society. Digital skills, which require some effort, should be developed to solve the problems associated with the ever-increasing volumes of heterogeneous and dynamically updated information.

Individual susceptibility to digital finance, the ability to extract the necessary information from a wide variety of sources, using information flows in real time, to establish hidden patterns in data sets and analyze them, the ability to constantly develop, keep up with the development of digital technologies will increase professional demand and financial security. Individual insensitivity, disregard for modern digital processes and lack of adaptation to the digital environment will lead to lost profits, loss of additional sources of income and, ultimately, to a deterioration in well-being.

Using digital financial products creates opportunity to make financial service more available to a wider range of consumers and business organizations.

Digitalization of finance provides wide investment opportunities, which effect on society's well-being.

1. External factors of 2020 become a trigger for the growth of digital investment activity in the stock market among Russian individuals of the working-age. The growth of private investment in the stock market has expanded for more than 2 times.

2. Novice Russian private investors prefer to inset in the assets of the fuel and energy sector of the Russian securities market as well as in bonds. They in common form medium-term and long-term stocks portfolios and do not have orientation for short-term speculative operations.

3. The susceptibility of individuals to digitalization of financial markets is depended from their individual cognitive reaction to the experience, emotions and information which they have got.

4. Trends in the globalization of digital financial markets for private investors indicate an increase in the process of material disintermediation towards virtual aggregators and digital intermediaries.

5. The digitalization allows to compensate for the professional imperfection of private investors. 


\section{REFERENCES}

[1] Orekhov, V., Prichina, O., Gizyatova, A., Kukharenko, O., Blinnikova, A. (2020). Development of the indicative system for assessing GDP per capita using cumulative indices, including human capital. Journal of Advanced Research in Dynamical and Control Systems. 12. S5. pp. 1139-1152

[2] Official NAFI site. [Electronical resource]. Access mode: https://nafi.ru/analytics/35-rossiyan-vzone-riska-izmerenie-urovnya-tsifrovoy-finansovoy-gramotnosti/

[3] Leven A.I., Suslov A.B. [Electronical resource]. Access mode: https://issek.hse.ru/mirror/pubs/share/377859003.pdf

[4] Official web-site of MOEX [Electronic resource] - Access mode: https://www.moex.com/s719

[5] Official web-site of Rosstat. [Eletronic rsource] - Access mode: https://www.moex.com/s719

[6] Gorshenin, V., Prichina, O., Orekhov, V., Pechurochkin, A., Aliukov, S. (2017). Cognitive technologies to build models for operation of business school. Proceedings of the 29th International Business Information Management Association Conference - Education Excellence and Innovation Management through Vision 2020: From Regional Development Sustainability to Global Economic Growth. pp. 504-513.. Trends in the globalization of digital financial markets for private investors indicate an increase in the process of material disintermediation towards virtual aggregators and digital intermediaries.

[7] Official web-site of RBC [Electronic resource]. Access mode: https://www.rbc.ru/finances/25/02/2021/603646a59a79471f3f239daa

\section{Article history:}

Received 14 April 2021

Accepted 10 July 2021 